\title{
A correlative study between maternal hemoglobin at third trimester and birth weight of babies born at Kathmandu Medical College, Teaching Hospital
}

\author{
Anup Shrestha ${ }^{1}$, Sabina Shrestha ${ }^{1}$ \\ ${ }^{\prime}$ Department of Pediatrics, Kathmandu Medical College, Teaching Hospital, Kathmandu, Nepal
}

\section{Keywords:}

Anemia;

Hemoglobin;

Low birth weight;

Preterm;

\begin{abstract}
Background: Anemia is one of the commonest health problems faced by pregnant women in both developing and developed countries. Maternal anemia is a potential risk factor for fatal outcomes like low birth weight and preterm delivery. This study intended at comparing the birth weight of the babies who were born to mothers with and without anemia during the third trimesters.
\end{abstract}

Materials and methods: This study is a descriptive, cross-sectional study conducted at Kathmandu Medical College, Teaching Hospital from July 2019 to June 2020. The third-trimester hemoglobin of mothers was recorded along with the birth weight of their respective babies. Mothers with regular antenatal care visits at this hospital were included and the known causes for anemia like renal disorders, twin pregnancies, and others were excluded from the study. The third-trimester hemoglobin level of all pregnant females was correlated with the birth weight of the babies.

Results: Out of a total of 2417 pregnant women, 317 (13\%) had anemia. The overall prevalence of low birth weight was $12 \%$. Out of 317 anemic mothers, $99(31 \%)$ delivered low birth weight babies. Among those 99 low birth weight babies, 30 (30\%) were preterm and 69 (70\%) were term babies with the prevalence of low birth weight in anemic mothers being $31 \%$. The correlation between maternal hemoglobin and birth weight was found to be statistically significant.

Conclusions: Despite regular antenatal care, maternal anemia still prevails, affecting neonatal birth weight. There was a statistically significant correlation between maternal hemoglobin and neonatal birth weight (p-value $<0.0001)$.

\section{Correspondence:}

Dr. Anup Shrestha, MBBS, MD

Lecturer, Department of Pediatrics

Kathmandu Medical College and Teaching hospital

Kathmandu, Nepal.

Orchid ID: 0000-0002-1872-6497

Email: anupsrestha@gmail.com

\section{Received : July $16^{\text {th }} 2020$; Accepted : September $26^{\text {th }} 2020$}

Citation: Shrestha A, Shrestha S. A correlative study between maternal hemoglobin at third trimester and birth weight of babies born at Kathmandu Medical College, Teaching Hospital. J Pathol Nep. 2020;10:1756-9. DOI: 10.3126/jpn.v10i2.30108

Copyright: This is an open-access article distributed under the terms of the Creative Commons Attribution 4.0 International License, which permits unrestricted use, distribution, and reproduction in any medium, provided the original author and source are credited.

\section{INTRODUCTION}

Anemia is defined as a condition in which the number of red blood cells (and consequently their oxygen-carrying capacity) is insufficient to meet the body's physiologic needs. ${ }^{1}$ It is one of the most commonly encountered health problems that affect $25 \%$ to $50 \%$ of the population of the world and approximately $50 \%$ of pregnant women. ${ }^{2}$

In pregnant women during the mid-trimester, there is a physiological fall in hemoglobin concentration. This fall is mainly due to the rise in plasma volume and consequent decline in hematocrit. Hemoglobin and hematocrit decline throughout the 1st and 2nd trimesters, reach 
their lowest point late in the second trimester to early 3 rd trimester, and then rise again nearer to term with peak hemodilution occurring during 24 to 26 weeks period of gestation. ${ }^{3}$ Placental circulation is improved because of this physiological change. The lowest point of this fall is erratic, and for this reason, there is a need for criteria to define anemia in pregnancy. ${ }^{4}$

According to WHO, hemoglobin level less than $11 \mathrm{gm} / \mathrm{dl}$ in pregnant women is defined as anemia and hemoglobin less than $7.0 \mathrm{gm} / \mathrm{dl}$ as severe anemia. ${ }^{5}$ The Center for Disease Control and Prevention (1990) defines anemia as Hb below $11 \mathrm{gm} / \mathrm{dl}$ in the first and third trimester and below $10.5 \mathrm{~g} / \mathrm{dl}$ in the second trimester. ${ }^{6}$

Danger due to anemia is not only related to the mother but to the growing fetus as well. Anemia in pregnancy is linked with amplified risk of maternal and perinatal mortality, premature delivery, low birth weight, and other adverse outcomes. ${ }^{7}$ In Asia, due to undernutrition in the mother before and during pregnancy the occurrence of low birth weight (LBW) is ubiquitous \& LBW is defined as a newborn weighing less than 2,500 grams at birth. ${ }^{8}$

One of the micronutrient deficiencies is maternal iron deficiency anemia (IDA), which has been linked to a higher risk of low birth weight, preterm delivery, and infant IDA. ${ }^{9}$ This can also permanently impair intelligence, motor, and behavioral development and increase the possibility of future IDA in the progeny. ${ }^{10}$ During childbearing age the amount of iron that is being consumed is too little to counterbalance the losses from menstruation and the increased demand linked with gestation. ${ }^{11,12}$ Studies entail that supplementation with iron or iron-folic acid should be started early in pregnancy if not before, to prevent low birth weight and preterm delivery. ${ }^{5}$

Maternal nutrition along with maternal hemoglobin concentration plays a vital role in the growth and development of the fetus. Fetal growth occurs in various phases and most of the micronutrient related issues occur in the third trimester.4 Hence, studying the impact of anemia during the third trimester on the fetal outcome would be more meaningful. We aimed at comparing the birth weight of the babies who were born to mothers with and without anemia in the third trimester.

\section{MATERIALS AND METHODS}

A descriptive, prospective cross-sectional study was carried out from 1st July 2019 to 30th June 2020 at Kathmandu Medical College and Teaching Hospital (KMCTH). Approval for the research was obtained from the ethical committee of KMCTH. All pregnant females with regular antenatal checkups ( $\geq 4$ visits) at KMCTH having laboratory reports of third-trimester hemoglobin levels were included in the study. Pregnant women who had maternal hemoglobinopathies, multiple pregnancies, systemic diseases such as hypertension, diabetes and renal diseases, intrauterine fetal death, and oligohydramnios were excluded from this study. Written consent along with brief history was taken and once the baby was delivered (via vaginal or cesarean section), a proforma was filled. Maternal hemoglobin levels (during the third trimester) performed by an automated Coulter counter machine were recorded. As per WHO guidelines, maternal hemoglobin of less than $11 \mathrm{gm} / \mathrm{dl}$ was labeled as maternal anemia. Newborns were weighed using an automatic weighing scale under proper supervision. Babies weighing less than 2500 grams were taken as low birth weight babies and those born before 37 weeks period of gestation were defined as preterm babies. Data were entered in Microsoft Excel and statistical analysis was done using statistical package for social sciences (SPSS) version 16.

\section{RESULTS}

The total number of cases enrolled in the study was 2417 deliveries. Maternal age ranged from 17 to 43 years with a mean age of 27 years. Majority of the babies were delivered via cesarean section $(1,340 ; 55.5 \%)$ followed by vaginal deliveries $(1,077 ; 44.5 \%)$, the ratio being $1.2: 1$. The period of gestation in this study ranged from $28-42$ weeks. There were 149 (6\%) preterm cases whereas 2268 (94\%) were term deliveries. (Table 1) The ratio of the term to preterm was 15.2:1.

Out of 2417 pregnancies, $317(13 \%)$ had anemia while $2100(87 \%)$ had a normal hemoglobin level. The overall prevalence of anemia in the third trimester was $13 \%$. The mean hemoglobin level was found out to be $12.2 \mathrm{~g} / \mathrm{dl}$. The mean birth weight of the newborn was $2960 \mathrm{~g}$. The weight of newborns ranged from 1.08 to $4.5 \mathrm{~kg}$. LBW was seen

\begin{tabular}{|c|c|c|c|}
\hline Sex & Male: Female & 1348: 1069 & $55.5: 44.5 \%$ \\
\hline Gestation & Term: Preterm & 2268: 149 & $94: 6 \%$ \\
\hline $\begin{array}{l}\text { Type of } \\
\text { delivery }\end{array}$ & $\begin{array}{l}\text { Normal vaginal } \\
\text { delivery: Cesarean } \\
\text { section }\end{array}$ & 1077: 1340 & $45: 55 \%$ \\
\hline Birth weight & $\begin{array}{l}\text { Low birth weight: } \\
\text { Normal weight }\end{array}$ & $296: 2121$ & $12: 88 \%$ \\
\hline
\end{tabular}

Table 2: Correlation between maternal anemia and birth weight

\begin{tabular}{|lcccc|}
\hline & $\begin{array}{c}\text { Low birth } \\
\text { weight } \\
\text { babies }\end{array}$ & $\begin{array}{c}\text { Normal } \\
\text { weight } \\
\text { babies }\end{array}$ & Total & $\begin{array}{c}\text { P-value } \\
(<\mathbf{0 . 0 5})\end{array}$ \\
$\begin{array}{l}\text { Mothers with } \\
\text { anemia }\end{array}$ & 99 & 218 & 317 & $<0.00001$ \\
\hline $\begin{array}{l}\text { Mothers with } \\
\text { normal Hb }\end{array}$ & 197 & 1903 & 2100 & \\
\hline Total & 296 & 2121 & 2417 & \\
\hline
\end{tabular}


in $296(12 \%)$ whereas 2121 (88\%) babies had weight more than $2500 \mathrm{~g}$. The overall prevalence of LBW was $12 \%$.

Out of 317 anemic mothers, 99 (31\%) delivered low birth weight babies. Among those 99 low birth weight babies, 30 $(30 \%)$ were preterm and $69(70 \%)$ were term intrauterine growth-retarded babies (IUGR) with the prevalence of LBW among anemic mothers being $31 \%$. The Odds ratio was 4.38 with a relative risk (RR) of 3.32 at $95 \% \mathrm{Cl}$. The $\mathrm{p}$-value was $<0.0001$. The correlation between maternal hemoglobin and birth weight was found to be statistically significant (p-value $<0.0001$ ). (Table 2)

\section{DISCUSSION}

Anemia is a global health problem affecting both developing and developed countries worldwide. A report of 2005 suggested that globally about 1.62 billion people (95\% CI: $1.50-1.74$ ) are affected by anemia, which is about $24.8 \%$ of the world's population. ${ }^{2}$ Anemia is the most prominent hematological manifestation in pregnant women. ${ }^{13}$ The prevalence of low birth weight babies is higher in Asia than anywhere else, mainly because of the lack of nutrition in mother prior to and during pregnancy. ${ }^{8}$

In our study, the prevalence of maternal anemia during the third trimester was $13 \%$ which is similar to a study done by Shobeiri et $\mathrm{al}^{14}$ who had a prevalence of $16 \%$ at some stage in the third trimester. Their study also stated that anemia was more prevalent in the first and second trimesters (45 to 49\%) respectively. In contrast to our study, research conducted by Wang et $\mathrm{al}^{7}$ from China established the overall prevalence of anemia during the third trimester of pregnancy to be $48.2 \%$.

Some of the studies done in Nepal took into account the severity of anemia and stated that severe anemia (hematocrit $<$ or $=24 \%$ ) was associated with a significantly increased risk of low birth weight $(<2500 \mathrm{~g})$ and preterm delivery $(<37$ weeks gestation) 15 . But, the severity of anemia was not taken into account in the present study because of the minuscule number of anemic pregnant mothers. Our study showed that the birth weight ranged from 1.08-4.5 kg with the prevalence of low birth weight as $12 \%$ which is similar to a study done by Kayastha et $\mathrm{a}^{16}(11.9 \%)$ in Nepal and $12.6 \%$ in a study done by Elhassan et $\mathrm{al}^{17}$ done at Sudan.

Anemic mothers were 3 times more prone to deliver LBW babies as compared to non-anemic mothers (Relative risk:3.3, Odds ratio: $4.3,95 \%$ Confidence interval, $\mathrm{p}$ value $<0.0001$ ). The present study correlates well with a study done by Levy et al.18 They stated that both preterm deliveries $(<37$ weeks gestation) and low birth weight $(<2500 \mathrm{~g})$ were found to be higher among patients with anemia as compared to the non-anemic women $(10.7 \%$ versus $9.0 \%, \mathrm{p}<0.001$ and $10.5 \%$ versus $9.4 \%, \mathrm{p}<0.001$; respectively). Similarly, Lone et $\mathrm{al}^{19}$ also showed that the risk of preterm delivery and LBW among the exposed group was 4 and 1.9 times higher among anemic women, respectively. They concluded that low maternal hemoglobin levels were associated with an increased risk of preterm delivery and LBW babies.

The correlation between maternal hemoglobin and birth weight was found to be statistically significant (p-value $<0.0001$ ) in the present study. Rusia et $\mathrm{al}^{20}$, Kumar et al,4 and Levy et $\mathrm{a}^{18}$ both had similar results in their study. The risks of preterm delivery and LBW increased in proportion to the severity of maternal anemia as stated by Kidanto et al. ${ }^{21}$

\section{CONCLUSIONS}

Maternal anemia during various trimesters may result in unpleasant outcomes, even more during the third trimester. Despite having regular antenatal care, maternal anemia is still a major health problem. Our result shows that maternal anemia during the third trimester significantly increases the risk of low birth weight. Maternal anemia can be prevented during pregnancy by providing health education and proper nutrition before pregnancy. Hence, further efforts are needed to decrease the incidence of maternal anemia which in turn reduces the low birth weight and its consequences in the newborn.

\section{ACKNOWLEDGEMENT}

I would like to express my sincere gratitude to my colleagues as well as staff (nurses, residents, and interns of the Department of Pediatrics and Department of Obstetrics). I would also like to thank our head of the department and all the laboratory and radiology technician for helping me out during the study period.

\section{Conflict of interest: None}

\section{REFERENCES}

1. WHO. Hemoglobin concentrations for the diagnosis of anaemia and assessment of severity. Vitamin and Mineral Nutrition Information System. Geneva, World Health Organization, 2011. Website

2. Ahankari A, Leonardi-Bee J. Maternal hemoglobin and birth weight: systematic review and metaanalysis. Int J Med Sci Public Health 2015;4:435-45. $\underline{\text { Crossref }}$

3. Bondevik GT, Ulstein M, Lie RT, Rana G, Kvale G. The prevalenceofanemiainpregnantNepaliwomen-astudyin Kathmandu.Acta Obstet Gynecol Scand 2000;79:341-9. Crossref

4. Kumar KJ, Asha N, Murthy DS, Sujatha MS, 
Manjunath V. Maternal anemia in various trimesters and its effect on newborn weight and maturity: An observational study. Int J Prev Med 2013;4:193-9. Website

5. World Health Organization (WHO). The global prevalence of anemia in 2011. World Health Organization; Geneva, Switzerland:2015. Website

6. Centers for Disease Control and Prevention (CDC) CDC criteria for anemia in children and childbearingaged women. Morb Mortal Wkly Rep 1989;38:400-4. Website

7. Wang J, Ren AG, Ye RWet al. Study on the third trimester hemoglobin concentrations and the risk of low birth weight and preterm delivery. Zhonghua Liu Xing Bing XueZaZhi 2007;28(1):15-8. $\underline{\text { Website }}$

8. Muthayya S. Maternal nutrition \& low birth weight-what is really important? Indian J Med Res 2009;130:600-8. Website

9. Skikne BS. Serum transferrin receptor. Am J Hematol 2008;83:872-5. Crossref

10. Allen L H. Anemia and iron deficiency: effects on pregnancy outcome. Am J ClinNutr2000;71:1280s84s. $\underline{\text { Crossref }}$

11. O Scholl T. Maternal iron status: relation to fetal growth, length of gestation and the neonate's iron endowment. Nutr Rev 2011;69:S23-9. Crossref

12. Alwan NA, Cade JE, McArdle HJ, at al. Maternal iron status in early pregnancy and birth outcomes: insights from the baby's vascular health and iron in pregnancy study. Br J Nutr 2015;113:1985-92. Crossref

13. Kumari S, Garg N, Kumar A, et al. Maternal and severe anemia in delivering women is associated with risk of preterm and low birth weight: A cross sectional study from Jharkhand, India. One Hlt 2019;8:100098. Crossref

14. Shobeiri F, Begum K, Nazari M. A prospective study of maternal hemoglobin status of Indian women during pregnancy and pregnancy outcome. Nut Res 2006;26:209-13. Crossref
15. Bondevik GT, Lie RT, Ulstein $M$ et al. Maternal hematological status and risk of low birth weight and preterm delivery in Nepal. Acta Obstet Gynecol Scand 2001;80:402-8. $\underline{\text { Crossref }}$

16. KayasthaS, TuladharH.Studyoflowbirthweightbabiesin NepalMedicalCollege. NepalMedCollJ2007;9:266-69. Website

17. Elhassan EM, Abbaker AO, Haggaz AD, et al. Anemia and low birth weight in Medani, Hospital, Sudan. BMC Res Notes 2010;3:181. Crossref

18. Levy A, Fraser D, Katz M, et al. Maternal anemia during pregnancy is an independent risk factor for low birth weight and preterm delivery. Eur J Obstet Gynecol Reprod Biol 2005;122:182-86. $\underline{\text { Crossref }}$

19. Lone FW, Qureshi RN, Emanuel F. Maternal anemia and its impact on perinatal outcome. Trop Med Int Health 2004;9:486-90. Crossref

20. Rusia U, Madan N, Agarwal N, et al. Effect of maternal iron deficiency anemia on fetal outcome. Indian J Pathol Microbiol 1995;38:273-79. Website

21. Kidanto HL, Mogren I, Lindmark $G$ et al. Risks for preterm delivery and low birth weight are independently increased by severity of maternal Anemia. S Afr Med J 2009;99:98-102. Website 